\title{
A reafirmação da fé no antigo relato da criação: uma abordagem semiótica do discurso católico
}

\author{
Sueli Maria Ramos da SILVA (FFLCH-USP)
}

RESUMO: Este artigo busca analisar semioticamente como a fé católica contemplada no Catecismo da Igreja Católica, ao imitar e captar o relato bíblico de Gênesis como texto de referência, imprime a este uma visão própria, que remete a um modo de ser, condizente com a ideologia em que se fundamenta.

PALAVRAS-CHAVE: divulgação religiosa; Catolicismo; Gênesis; discurso; éthos.

\begin{abstract}
We aim to examine by the semiotics theory how the catholic faith, contemplated in the Catholic church's catechism, imitates and captivates Genesis as a reference text, and gives to it a particular vision that refers to a way of being, corresponding to the ideology in which it is based on.
\end{abstract}

KEYWORDS: Religious spreading; Catholicism; Genesis; discourse; éthos. 


\section{Introdução}

A crença, tal como presente no Dicionário de semiótica, de autoria de GREIMAS, A.J. (1989: 91-92), entendida "enquanto adesão do sujeito ao enunciado de um estado", apresentada "como um ato cognitivo, sobredeterminado pela categoria modal da certeza", presente em diversas instâncias discursivas e não apenas como fundamento da fé religiosa, seria, segundo o autor, um tema recorrente às pesquisas semióticas dos anos vindouros. Porém, no que concerne ao estabelecimento da crença como fundamento da fé presente nos discursos de divulgação religiosa, recorte para o qual buscamos estabelecer para a realização da presente proposta, no que diz respeito aos estudos no âmbito da Semiótica e da Análise do Discurso que já teriam versado sobre o mesmo tema, o que podemos observar é uma escassez considerável de estudos a esse respeito. Assim, podemos ressaltar, dentre aqueles a que foi possível ter acesso, e dos quais utilizamos como base para a elaboração da presente proposta, as análises realizadas por DELORME, J. \& GEOLTRAIN, P. (1982); DISCINI, N. (2005); FIORIN, J.L. (1988); PANIER, Louis (1986); MAINGUENEAU, D. (2005) e ORLANDI, E. (1996).

Assim, dentro dos propósitos e limitações de um trabalho desta natureza, propomos uma contribuição ao desenvolvimento de pesquisas em análise do discurso de divulgação religiosa.

\section{Objetivos}

Nesta análise, tendo por fundamentação teórica a Semiótica Greimasiana e a Análise do Discurso (AD) francesa, propomos o estudo do relato bíblico do livro de Gênesis, buscando analisar a maneira pela qual este livro, no que concerne aos elementos de criação do mundo e da raça humana, é apregoado pela religião católica por meio de seu Catecismo, de valor doutrinário e instrucional.

Assim, a partir da análise do Catecismo, enquanto enunciado divulgador do livro de Gênesis, será descrito o estilo ou o éthos desse gênero textual, que ao imitar e captar o relato bíblico de Gênesis confere a este um ponto de vista próprio, que remete a um modo de ser próprio do sujeito a ele pressuposto e à formação ideológica da qual faz parte.

\section{Corpus}

O livro de Gênesis, sendo este o primeiro livro do Pentateuco presente no Antigo Testamento das Escrituras Hebraicas Cristãs, utilizado como fonte principal para a elaboração da catequese referente aos mistérios do princípio, encontra-se presente no primeiro capítulo da segunda seção do Catecismo da Igreja Católica, referente à profissão de fé cristã, concernente ao símbolo da fé católica na crença em Deus Pai todo-poderoso como o criador do céu e da terra, tal como revelado nas escrituras para honra e glória divinas. A ordem seguida para esta exposição catequética refere-se à exposição da criação, queda e promessa de salvação.

O recorte analítico ao qual procedemos para a realização da presente análise consiste das páginas iniciais do parágrafo quatro (pp.83-86), presente no primeiro 
capítulo da segunda seção do Catecismo da Igreja Católica: Edição Típica Vaticana, referente à catequese sobre a criação.

\section{Análise do discurso católico}

Inicialmente, se tomarmos como ponto de partida os desenvolvimentos efetuados por PANIER (1986), sem levar em conta o gênero discursivo do texto recortado para os propósitos dessa análise, poderíamos defini-lo, segundo o autor, sob a denominação de "discurso comentário", dado que se realiza enquanto um discurso de interpretação do relato bíblico, no caso, o relato bíblico de Gênesis, tido como discurso fundador da unidade recortada. O "discurso comentário" é visto, portanto, como um discurso segundo, equivalente do ponto de vista do sentido ao discurso fundador (relato bíblico) que toma por objeto, em que se configura a passagem de um texto figurativo (relato bíblico) a um texto não-figurativo ("discurso comentário"). De tal forma que esse discurso apresenta as seguintes categorias de desempenho: o fazer comunicativo ou persuasivo, no qual o comentário opera com a transmissão de um saber que se coloca como a verdade, e um fazer interpretativo, no qual "o comentário interpreta a narrativa que toma por objeto." (PANIER, 1986: 268) Assim, de posse dessas noções, torna-se possível proceder à identificação do texto recortado para a presente análise.

O Catecismo se constitui como um gênero textual pertencente à esfera de circulação do discurso religioso, relativo às atividades institucionalizadas da prática religiosa católica. Nesse âmbito, o discurso religioso se configura como uma esfera de circulação (cena englobante), na qual circula o gênero (cena genérica) do discurso de "divulgação religiosa" /catecismo.

O gênero catecismo apresenta como elementos constitutivos de sua temática os símbolos da fé religiosa e da doutrina católica, podendo-se citar a presença dos seguintes temas: tema da beligerância necessária à constituição do sujeito; tema da perfeição do homem; tema da incondicionalidade do dogma; tema da dependência entre salvação/dogma; tema da irrestrição da entrega a Deus e, portanto, o abandono das coisas do mundo; tema da fidelidade obrigatória à Igreja; tema do pecado original (confissão).

Sua estrutura composicional da qual faz parte o tipo textual injuntivo presente nesta modalidade de texto instrucional programador, na medida em que possibilita a aquisição de uma competência, no caso, os atributos necessários para ser católico, é pautada por uma estrutura textual em constante alusão intertextual e referência às Sagradas Escrituras. De tal modo que, no que concerne à coerção genérica de sua exposição, apresenta como estrutura composicional a articulação de seu conteúdo disposto em quatro partes: A profissão de fé (exposição do Credo), A celebração do mistério cristão (a sagrada Liturgia), A vida em cristo (exposição do agir cristão) e a oração cristã.

O catecismo consultado e tomado para a análise confirma o éthos prévio dado pelo gênero catecismo enquanto manual de ensino pra explicar a doutrina cristã, entretanto, como se configura como uma edição típica, não se apresenta estruturado na forma de perguntas e respostas. Seu estilo é baseado em uma linguagem formal, ausente de adaptações relativas ao público, dado que se configura como uma edição típica, 
destinada a servir como base à construção dos catecismos locais de diversos países. Assim, apresenta fundamentalmente como leitores pressupostos, além dos fiéis católicos que quiserem se aprofundar em sua doutrina, os responsáveis pela tarefa de catequização (bispos, doutores da fé e pastores da igreja).

Partindo do princípio de que a apreensão do sentido dos textos não é algo exterior e apriorístico ao signo, mas resultante da reunião dos dois planos compreendidos na linguagem (o plano da expressão e o plano do conteúdo), levando em consideração a ideologia em que se fundamentam tais discursos, bem como os julgamentos de valor e atitudes expressos pela sociedade, buscar-se-á no recorte analítico proposto, analisar semioticamente como a fé católica contemplada no Catecismo da Igreja Católica constrói miticamente o mundo e a humanidade no ato de sua criação original manifestada pelo verbo divino, presente nos três primeiros capítulos do livro de Gênesis das Sagradas Escrituras.

Tendo como pressuposto que o texto presente no Catecismo só ganha seu sentido na prática religiosa da lógica do discurso religioso católico, para que seja possível a depreensão do sentido do texto em pauta, procederemos à construção do procedimento teórico metodológico do percurso gerativo do sentido, para que possamos analisar como este discurso se configura. Assim, ao se estabelecer um percurso gerativo de significação, baseando-nos inicialmente numa oposição semântica fundamental, representativa da organização mínima do texto, podemos inicialmente depreender as relações fundamentais estabelecidas por meio da visualização do seguinte quadrado semiótico:

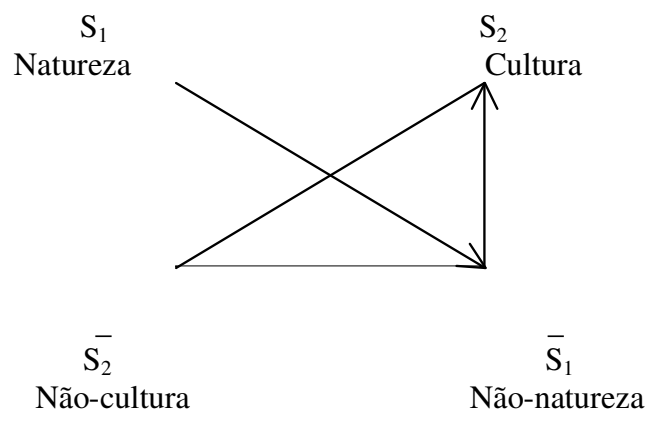

Ao analisarmos o quadrado tal como exposto, podemos perceber que a oposição semântica fundamental é estabelecida no texto entre os termos contrários (natureza e cultura) e contraditórios (não-natureza e não-cultura), sendo a natureza representativa das pulsões individuais e naturais do indivíduo e a cultura à submissão do indivíduo pelo domínio social ritualizado por meio da prática religiosa representada pelo catolicismo e a conseqüente crença nos valores propostos por tal doutrina. A ideologia católica se faz presente neste momento considerando como valores prescritos por sua doutrina a crença na palavra tal como apregoada, ou seja, a crença na criação 
divina tal como presente nas sagradas escrituras. Como não prescritos e consequentemente transgressores da crença e moral católicas e de tendência disforizante estariam aqueles que se puserem a contestá-la por meio de respostas divergentes à questão das origens.

Assim, os termos do quadrado são axiologizados da seguinte forma: os termos (cultura e não-natureza) são axiologizados com valores eufóricos e (natureza e nãocultura) com valores disfóricos. De tal maneira que se tem a seguinte relação entre os termos do quadrado: o termo "cultura" aparece como uma prescrição católica e, portanto, como uma injunção positiva; "natureza" aparece como uma interdição (injunção negativa); "não-natureza" aparece como uma não-interdição (não injunção negativa) e "não-cultura" como uma relação não prescrita (não injunção positiva).

No que concerne à narratividade imanente a este discurso vê-se que sua constituição é baseada na instalação de um programa narrativo (PN) de crença, tal como se segue:

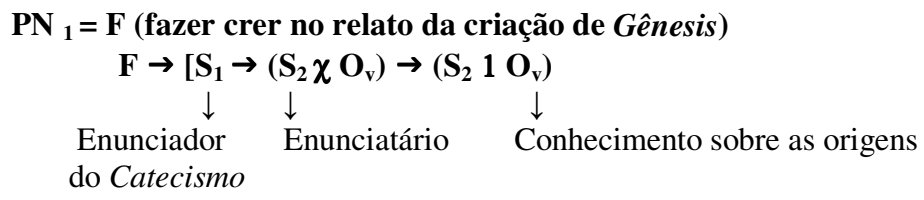

O destinador manipulador $\left(\mathrm{S}_{1}\right)$ representado pelo enunciador (representante da Igreja), sendo este o enunciatário do enunciador superior (hiperenunciador) representado pela figura divina, por meio de um programa narrativo baseado em um contrato fiduciário, busca persuadir o enunciatário a entrar em conjunção com o objeto de valor representado pelo conhecimento sobre as origens, para o qual ele se mostra inicialmente disjunto, para que este adquira a competência necessária para sua transformação num sujeito religioso cristão.

Notamos que no trecho em análise, tal como delimitado no item referente à apresentação do corpus desta pesquisa, não se fazem presentes todas as etapas do esquema narrativo canônico apresentado segundo FLOCH (2001: 23) como a seguinte seqüência ordenada: Contrato $\rightarrow$ Competência $\rightarrow$ Performance $\rightarrow$ Sanção.

$\mathrm{O}$ trecho apresenta-se dividido em dois segmentos, sendo o primeiro deles referente à apresentação da temática concernente ao símbolo da fé católica na crença em Deus Pai todo-poderoso como criador do céu e da terra e o segundo à exposição sumária acerca da catequese sobre a criação.

O destinador-manipulador (Papa, Conselho de Cardeais e Bispos), revestido pelo poder que lhe foi delegado como máxima autoridade representante da Igreja e pela referência à palavra revelada, dirige-se ao destinatário-sujeito (fiéis cristãos e responsáveis pela catequese), por meio da construção do simulacro negativo do pathos deste enunciatário disjunto de uma resposta adequada à questão das origens. A eficácia deste discurso se exerce por meio do reconhecimento da autoridade daquele que o profere, repousando esta por meio da crença na palavra revelada como garantia da salvação. Assim, o destinador-manipulador busca estabelecer um contrato fiduciário 
com o destinatário-sujeito por meio da crença na palavra revelada pela divindade, obtida e conservada por intermédio da religião católica.

$\mathrm{O}$ texto se inicia com referência às Sagradas Escrituras, especificamente ao relato bíblico de Gênesis: "No princípio, Deus criou o céu e a terra (Gn 1,1)” (pp.83), para selar o contrato inicial proposto pelo destinador manipulador ao destinatário sujeito, repousar o reconhecimento de sua autoridade e obter a confiança do destinatário por meio da crença, expressa pela palavra revelada como obra do sujeito absoluto, Deus, reafirmando a crença sobrenatural da garantia da salvação.

O Símbolo da fé, também denominado "profissão de fé", enquanto síntese da fé professada pelos cristãos, reforça o argumento de autoridade de que se vale o destinador-manipulador ao afirmar que este, ao retomar as palavras das Sagradas escrituras, não é elaborado mediante opiniões humanas, mas é comandado pela palavra revelada por meio das Escrituras, numa ordem de exposição que segue os antigos Símbolos da fé, respectivamente o Símbolo dos Apóstolos e o nicenoconstantinopolitano, utilizados nas diferentes etapas da Igreja Católica.

Deste modo, o texto em pauta, por meio do dialogismo imanente que o constitui, tendo como coerções genéricas a presença de citações das Sagradas Escrituras e referência aos demais Símbolos da fé professados em diferentes fases da Igreja como argumento de autoridade, na medida em que estabelece também um dialogismo com outros textos que se confrontam com as respostas dadas pela fé cristã em referência à questão das origens, presentes na referência às pesquisas científicas, filosofia, religiões e culturas antigas, se tomarmos as acepções estabelecidas por AUTHIER-REVUZ (1982) em seu desenvolvimento dos princípios do dialogismo bakhtiniano, realiza-se de forma mostrada, ou seja, apresentando o "outro" em sua própria configuração discursiva. Tal característica, longe de configurar um efeito de polifonia, o configura como um relato monofônico dotado de um caráter de autoridade, visando, por conseguinte, manipular o leitor por meio de uma narratividade presente tanto no relato bíblico do livro de Gênesis, quanto no próprio texto do Catecismo. Busca assim, fazer com que o fiel encontre neste livro a adequada resposta à questão das origens, tal como revelada no Gênesis das sagradas Escrituras do qual se utilizam como "fonte principal para a catequese dos Mistérios do 'princípio': criação, queda, promessa de salvação" (p.86). De tal modo que os valores ideológicos do catolicismo respaldados pelas Sagradas Escrituras são euforizados em oposição às respostas divergentes à questão das origens que se confrontam com a fé professada pelo catolicismo.

Assim, por meio de um programa narrativo baseado em um contrato fiduciário, o destinador-manipulador busca convencer o destinatário sujeito por meio do argumento de autoridade expresso pela referência à palavra divina, a Luz de Cristo e a Tradição viva da Igreja.

A modalização deôntica, pela apresentação de um percurso de ação dado por meio do discurso de um fazer-dever-fazer instaurado pelo destinador, ao operar com a revelação dos saberes a respeito do enunciador divino, busca a adesão do destinatário por meio da manipulação executada na ordem do poder, em que são propostas ao mesmo tempo, tentações e intimidações.

Este discurso, ao estabelecer um lugar de mediação entre o destinador divino superior e o saber enunciado por meio da Palavra Revelada com aqueles destinatários a 
quem se busca atingir, por meio de seus textos instrucionais e propagadores da doutrina das Sagradas Escrituras, constrói uma espécie de manipulação pra que o leitor (actante coletivo), tendo sido persuadido e aderido ao objeto do saber, e, portanto, deonticamente modalizado, queira aprender os fundamentos bíblicos em conformidade com a ideologia católica que os fundamenta. Assim, busca levar o enunciatário, por meio da modalização deôntica, à aquisição da competência esperada com o comprometimento com a palavra divina, levando-o à conjunção com o objeto de valor que estaria representado na busca de uma resposta à questão das origens.

O homem para entrar em conjunção com o objeto de valor almejado deve concordar com o contrato estabelecido. Tendo adquirido a competência de um deverfazer e de um querer-fazer, deve realizar a performance de crença e glorificação da criação compreendida na catequese dos princípios como obra da Santíssima Trindade.

Assim, tendo o fiel católico como leitor pressuposto, o "outro" ao qual este discurso se destina, o destinador do texto católico estabelece uma catequese sobre a criação para fazer com que o leitor por meio de uma manipulação baseada na intimidação (se o fiel não crer na palavra divina não obterá a salvação), aceite seu relato, cristalize sua fé em Deus e consequentemente seja sancionado positivamente com a salvação. Apenas as etapas referentes ao estabelecimento do contrato e da doação de competência são efetivamente realizadas, ficando as etapas de performance e sanção apenas subentendidas com o cumprimento do programa narrativo de uso pelo destinatário.

No nível discursivo, último nível do percurso gerativo do sentido, a organização narrativa concretiza-se em discurso graças aos procedimentos de desembreagem e embreagem actancial, temporal e espacial da sintaxe discursiva, bem como por meio da semântica discursiva, graças aos procedimentos de tematização e figurativização responsáveis pelo investimento e concretização dos valores disseminados no nível narrativo.

Ao procedermos à análise das estruturas discursivas do referido texto, concernentes à temporalização, espacialização e actorialização das ações e estados narrativos, podemos depreender a presença de uma debreagem enunciva pautada por um efeito de objetividade e distanciamento da enunciação pelo emprego da terceira pessoa e da espacialização como um lá. Também observamos o emprego de um "nós" exclusivo, pois este, ao mesmo tempo em que aproxima enunciador e enunciatário, também os separa, dado o poder e saber conferidos a este enunciador. A presença de citações das Sagradas Escrituras colocadas em discurso direto, por meio do simulacro de realidade instaurado por meio da delegação da voz a este enunciador divino, também é responsável pelo caráter de autoridade conferido ao discurso do Catecismo. A temporalização é dada pela utilização do presente omnitemporal, na medida em que a fé na criação e doutrina católicas determinada pelo sacramento da fé deve ocorrer em toda e qualquer época.

Deste modo, vejamos como se constroem os procedimentos de tematização e figurativização imanentes ao catecismo.

O Catecismo, no primeiro capítulo da segunda seção referente à "profissão de fé cristã", enquanto resumo da fé professada pelos cristãos, representa em sua configuração temática, a busca, figurativizada no próprio título por meio da fé, de uma 
resposta adequada à questão das origens, pelo seguinte revestimento temático: tema da incondicionalidade do dogma; tema da incondicionalidade e veracidade do relato bíblico; tema da perfeição do homem; tema da dependência entre salvação/dogma; tema da fidelidade obrigatória à Igreja e o tema do pecado original (confissão). Deste modo, vejamos como esses temas, encadeados por meio do percurso temático da busca de uma resposta adequada à questão das origens, recebem seu revestimento figurativo ao longo do Catecismo por meio de elementos sensoriais próprios ao discurso religioso, e como seu encadeamento figurativo ao longo do texto representa a concretização dos temas anteriormente mencionados.

Estes temas recebem o seguinte investimento figurativo:

- Símbolo da fé: Figurativiza a fé na garantia sobrenatural da salvação, por meio da religião. Enquanto "resumo da fé" professada pelos católicos, se configura como um "sinal de reconhecimento e comunhão entre os crentes". (p.60) A referência ao "símbolo da fé" recobre figurativamente o procedimento temático representado por meio da crença na palavra revelada, pois por meio deste símbolo, a partir do momento em que se recita a fé no credo, entra-se em comunhão com a Santíssima Trindade (Pai, Filho e Espírito santo) e com a Igreja Católica.

- Aliança: figurativiza o estabelecimento do contrato inicial baseado na crença e adesão à palavra revelada, para que se possa alcançar a aliança (conjunção) com DeusPai como o criador do céu e da terra.

- Céu e Terra: concretização sensorial da criação estabelecida pelo criador em sua onipotência.

- Deus: figurativização e concretização da garantia sobrenatural da salvação situada como obra de um sujeito onipotente e onisciente. Concretização da crença na palavra revelada ou testemunhada por uma entidade divina.

- Jesus Cristo: A fé católica em Deus criador dá-se na pessoa de Jesus, palavra e revelação divina. A concretização da fé em Deus criador na pessoa de Jesus se dá por meio da fé professada no primeiro sacramento instituído por Jesus como auxiliar à salvação.

As possibilidades de leitura permitidas por um determinado texto são determinadas pela noção de isotopia enquanto reiteração discursiva de temas e redundância das figuras como meio capaz de garantir sua coerência semântica.

Assim, ao procedermos à análise do texto instrucional notamos que se trata de um texto predominantemente temático, cuja possibilidade de leitura se inscreve unicamente dentro da isotopia religiosa, especificamente católica, sendo revestido esparsamente por figuras que buscam concretizar a crença sobrenatural na salvação realizada por uma entidade transcendente e onipotente representada por Deus-Pai e por Jesus Cristo, sendo este último representativo de uma maior concretização referente a esta questão.

Entretanto, ao se tratar o modo pelo qual se dá o investimento temático e figurativo do texto em análise, deve-se levar em conta o éthos e a ideologia a ele subjacentes, na medida em que o texto, qualquer que seja o seu gênero discursivo, busca reproduzir o imaginário social.

Tanto os discursos temáticos, por meio do tratamento mais abstrato do conteúdo, pautados pela classificação e organização da realidade significante, com o 
estabelecimento de relações e dependências temáticas; quanto os discursos figurativos, por meio da concretização sensorial dos temas, responsáveis pelos efeitos de realidade, sofrem determinações sociais, sendo o lugar por excelência das determinações ideológicas, de tal modo que a relação entre temas e figuras assinala claramente a posição ideológica de seu destinador em conformidade com os valores ideológicos a que este se filia.

De tal modo que o éthos (tom, voz, caráter e corporalidade) subjacente aos textos, construído por uma recorrência de características observáveis no plano do conteúdo e no plano da expressão, pode ser recuperado por meio da apreensão do sujeito em relação ao enunciado, no que diz respeito à conversão de percursos narrativos em percursos temáticos e seu posterior revestimento figurativo, com vistas a se criar efeitos de realidade, de tal modo que o discurso não se torna a representação do real, mas a criação de efeitos de realidade, mediados pela enunciação.

Assim, tendo tomado nesta análise o corpus da religião cristã, no recorte católico, apreensível em seu Catecismo de valor doutrinário e instrucional, vemos que este discurso serve como mediador entre um destinador divino superior e aqueles destinatários a quem se busca atingir (pathos), seja em primeiro lugar os responsáveis pela catequese (bispos, doutores da fé e pastores da Igreja) ou a todos os demais fiéis cristãos. Por meio de um éthos de tom de voz altivo e superior, autoritário e detentor de uma verdade inquestionável, pois respaldado pela autoridade das Sagradas Escrituras, e pelo poder conferido a este enunciador, representado pela autoridade papal, e, portanto o nível mais elevado da hierarquia católica, tem por fím último a crença e a obediência na palavra tal como apregoada nas Sagradas Escrituras e a conseqüente adesão pela fé aos mistérios da criação obtidos por meio da revelação divina da criação do mundo para a glória e celebração divinas. Assim, o modo de ser próprio do enunciador do catecismo busca a adesão de sua imagem pelo enunciatário pressuposto a este discurso, que deve, por conseguinte, partilhar das crenças e valores propostos pelo catolicismo.

O símbolo da fé cristã se configura como o resumo da fé professada pelos cristãos, sinal de reconhecimento e comunhão entre aqueles partidários da mesma formação ideológica representada pelo catolicismo. Este símbolo divide-se em três partes compreendidas como as verdades na qual o fiel católico deve depositar sua crença. A crença em Deus como o Criador, recorte ao qual se estabeleceu durante a realização da presente análise é representativa da primeira e mais fundamental afirmação da profissão do símbolo da fé cristã, a ser realizada por ocasião do batismo, para que se possa alcançar a salvação.

Assim, busca-se a afirmação da crença em um Deus criador transcendente e onipotente que dá origem ao mundo de forma linguageira, ou seja, pelo verbo. Desse modo, o relato da criação é utilizado como o testemunho primeiro e universal do amor todo-poderoso de Deus e explicativo da origem do mal e de sua redenção pelo homem. Deste modo, uma das provas de sua existência é a revelação da criação expressa na mensagem dos profetas, nas orações dos salmos, na liturgia, na reflexão do povo eleito e, sobretudo nos primeiros capítulos do livro de Gênesis utilizados como fundamento à catequese sobre a criação.

\section{Considerações finais}


Este artigo se propôs ao estudo da maneira pela qual o relato bíblico de Gênesis, ao ser imitado e captado pelo Catecismo da Igreja Católica, utilizado como fonte principal à catequese referente aos mistérios do princípio, apresenta a inserção de um modo de ser próprio ao sujeito a ele pressuposto, condizente com a ideologia católica ao qual este se filia. Para a elaboração desta proposta procedemos inicialmente ao estabelecimento do percurso gerativo do sentido, para em seguida nos ocuparmos da análise e descrição do éthos desta instituição, a fim de se proceder ao exame de como e porque a fé contemplada no catolicismo constrói miticamente o mundo e a humanidade em seu ato de criação original.

Assim, espera-se que por meio deste trabalho, resultado de nossa curiosidade e interesse pelos discursos de "divulgação religiosa", somados a escassez de estudos feitos a esse respeito no âmbito da Semiótica e Análise do Discurso (AD), possa ter

contribuído de alguma forma ao desenvolvimento de pesquisas em análise do discurso religioso de base bíblica.

\section{REFERÊNCIAS BIBLIOGRÁFICAS}

AUTHIER-REVUZ, J. Hétérogéneité montrée et hétérogéneité constitutive : élements pour une aprouche de l'autre dans le discours. In: DRLAV: Paris: Centre de Recherches de l'Université de Paris, Revue de Linguistique, VIII, n.26, 1982, pp. 91151.

DELORME, J. \& GEOLTRAIN, P. Le discours religieux. In: COQUET, J.C. Semiotique : l'école de Paris, Hachette, 1982.

DISCINI, Norma. A Comunicação nos Textos. São Paulo: Contexto, 2005.

FIORIN, José Luiz. O Regime de 1964: Discurso e Ideologia. São Paulo: Atual, 1988.

FLOCH, Jean-Marie. Alguns conceitos fundamentais em semiótica geral. São Paulo: Centro de Pesquisas Sociossemióticas, 2001.

GREIMAS, A.J. Dicionário de Semiótica. São Paulo: Cultrix, 1989.

GREIMAS, A.J. e RASTIER, F. O jogo das restrições semióticas. In: GREIMAS, A.J. Sobre o sentido: ensaios semióticos. Petrópolis: Vozes, 1975.

JADON, José Carlos. A ideologia do sucesso: uma análise semiótica do discurso televisivo da Igreja Universal do Reino de Deus. Dissertação de Mestrado. São Paulo: Universidade Presbiteriana Mackenzie, 2005.

MAINGUENEAU, Dominique. A Gênese dos discursos. Curitiba: Criar Edições, 2005.

ORLANDI, E. A Linguagem e seu funcionamento: As formas do discurso. $4^{\mathrm{a}}$.ed. Campinas : Pontes, 1996.

Discurso Fundador. $3^{\mathrm{a}}$. ed. Campinas: Pontes, 2003.

PANIER, L. O discurso de interpretação no comentário bíblico. In: GREIMAS, A.J. e LANDOWSKI, E. Análise do Discurso em Ciências Sociais. São Paulo: Global, 1986.

PAULO II, João. Catecismo da Igreja Católica: Edição Típica Vaticana. São Paulo: Loyola, 2000.

SATIDRIÁN, Pedro R. Dicionário básico das religiões. São Paulo: Editora Santuário, 1996. 


\section{ANEXO}

PAUlO II, João. Catecismo da Igreja Católica: Edição Típica Vaticana. São Paulo: Vozes, 2000. p. 83-86.

\section{PARÁGRAFO 4 \\ O CRIADOR}

"No princípio, Deus criou o céu e a terra" (Gn 1,1). Com essas solenes palavras inicia-se a Sagrada Escritura. O Símbolo da fé retoma estas palavras confessando Deus Pai todo-poderoso como "o Criador do céu e da terra", "de todas as coisas visíveis e invisíveis" . Por isso, falaremos primeiro do Criador, em seguida de sua criação e, finalmente, da queda no pecado, do qual Jesus Cristo, o Filho de Deus, veio resgatarnos.

A criação é o fundamento de "todos os desígnios salvíficos de Deus", "o começo da história da salvação", que culmina em Cristo. Inversamente, o mistério de Cristo é a luz decisiva sobre o mistério da criação; ele revela o fim em vista do qual, "no princípio, Deus criou o céu e a terra" (Gn 1,1): desde o início, Deus tinha em vista a glória da nova criação em Cristo ${ }^{4}$.

É por isso que as leituras da Vigília pascal, celebração da criação nova em Cristo, começam pelo relato da criação; da mesma forma, na liturgia bizantina, o relato da criação constitui sempre a primeira leitura das vigílias das grandes festas do Senhor. Segundo o testemunho dos antigos, a instrução dos catecúmenos para o batismo segue o mesmo caminho 5 .

\subsection{A catequese sobre a criação}

A catequese sobre a criação se reveste de uma importância capital. Ela diz respeito aos próprios fundamentos da vida humana cristã, pois explicita a resposta da fé cristã à pergunta elementar feita pelos homens de todas as épocas: "De onde viemos?" Para onde vamos?" "Qual a nossa origem?" "Qual é o nosso fim?" "De onde vem e para onde vai tudo o que existe?" As duas questões, a da origem e a do fim, são inseparáveis. São decisivas para o sentido e a orientação de nossa vida e do nosso agir.

A questão das origens do mundo e do homem é objeto de numerosas pesquisas científicas que enriqueceram magnificamente nossos conhecimentos sobre a idade e as dimensões do cosmo, o devir das formas vivas, o aparecimento do homem. Essas

\footnotetext{
${ }^{1}$ Símbolo dos Apóstolos: DS 30.

${ }^{2}$.Símbolo niceno-constantinopolitano: DS 150.

${ }^{3}$ DCG 51.

${ }^{4}$ Cf. Rm 8,18-23

${ }^{5}$ Cf. Etéria, Pereg. 46 PLS 1,1047; Sto. Agostinho, De cathechizandis rudibus, 3.5: PL $40,256$.
} 
descobertas nos convidam a admirar tanto mais a grandeza do Criador, a render-lhe graças por todas as suas obras, pela inteligência e sabedoria que dá aos estudiosos e pesquisadores. Com Salomão, estes últimos podem dizer: "Ele me deu um conhecimento infalível dos seres para entender a estrutura do mundo, a atividade dos elementos... pois a Sabedoria, artífice do mundo, mo ensinou" (Sb 7, 17, 22).

$\mathrm{O}$ grande interesse reservado a essas pesquisas é fortemente estimulado por uma questão de outra ordem e que ultrapassa o âmbito próprio das ciências naturais. Não se trata somente de saber quando e como surgiu materialmente o cosmo, nem quando o homem apareceu, mas, antes, de descobrir qual é o sentido de tal origem: se ela é governada pelo acaso, um destino cego, uma necessidade anônima, ou por um Ser transcendente, inteligente e bom, chamado Deus. E, se o mundo provém da sabedoria e da bondade de Deus, por que existe o mal? De onde vem? Quem é o responsável por ele? Haverá como libertar-se dele?

Desde os inícios, a fé cristã tem-se confrontado com respostas diferentes da sua no que diz respeito à questão das origens. Assim, encontram-se nas religiões e nas culturas antigas numerosos mitos acerca das origens. Certos filósofos afirmaram que tudo é Deus, que o mundo é Deus, ou que o devir do mundo é o devir de Deus (panteísmo); outros afirmaram que o mundo é uma emanação necessária de Deus, emanação esta que deriva dessa fonte e volta a ela; outros ainda afirmaram a existência de dois princípios eternos, o Bem e o Mal, a Luz e as Trevas, em luta permanente entre si (dualismo, maniqueísmo); segundo algumas dessas concepções, o mundo (pelo menos o mundo material) seria mau, produto de uma queda, e portanto deve ser rejeitado ou superado (gnose); outros admitem que o mundo tenha sido feito por Deus, mas à maneira de um relojoeiro que, uma vez terminado o serviço, o teria abandonado a si mesmo (deísmo); outros, finalmente, não aceitam nenhuma origem transcendente do mundo, vendo neste o mero jogo da matéria que teria existido sempre (materialismo). Todas essas tentativas dão prova da permanência e da universalidade da questão das origens. Esta busca é própria do homem.

Sem dúvida, a inteligência humana já pode encontrar uma resposta para a questão das origens. Com efeito, a existência de Deus Criador pode ser conhecida com certeza por meio de suas obras, graças à luz da razão humana ${ }^{6}$, ainda que este conhecimento seja muitas vezes obscurecido e desfigurado pelo erro. É por isso que a fé vem confirmar e iluminar a razão na compreensão correta desta verdade. "Foi pela fé que compreendemos que os mundos foram formados por uma palavra de Deus. Por isso é que o mundo visível não tem sua origem em coisas manifestas” (Hb 11,3).

A verdade da criação é tão importante para toda a vida humana que Deus, em sua ternura, quis revelar a seu Povo tudo o que é útil conhecer a este respeito. Para além do conhecimento natural que todo homem pode ter do Criador ${ }^{7}$, Deus revelou progressivamente a Israel o mistério da criação. Ele, que escolheu os patriarcas, que fez Israel sair do Egito e que, ao escolher Israel, o criou e o formou ${ }^{8}$, se revela como Aquele

${ }^{6}$ Cf. DS 3026.

${ }^{7}$ Cf. At 17, 24-29; Rm 1,19-20.

${ }^{8} \mathrm{Cf}$. Is 43,1 . 
a quem pertencem todos os povos da terra, e a terra inteira, como o único que "fez o céu e a terra" (S1 115, 15; 124, 8; 134, 3).

Assim a revelação da criação é inseparável da revelação e da realização da Aliança de Deus, o único, com o seu Povo. A criação é revelada como sendo o primeiro passo rumo a esta Aliança, como o testemunho primeiro e universal do amor todo-poderoso de Deus9. Além disso, a verdade da criação se exprime com um vigor crescente na mensagem dos $\operatorname{profetas}^{10}$, na oração dos $\operatorname{salmos}^{11}$ e da liturgia, na reflexão da sabedoria $^{12}$ do Povo eleito.

Entre todas as palavras da Sagrada Escritura sobre a criação, os três capítulos do livro de Gênesis ocupam um lugar único. Do ponto de vista literário, esses textos podem ter diversas fontes. Os autores inspirados puseram-nos no começo da Escritura, de sorte que eles exprimem em linguagem solene, as verdades da criação, da origem e do fim desta em Deus, de sua ordem e de sua bondade, da vocação do homem e finalmente do drama do pecado e da esperança da salvação. Lidas à luz de cristo, na unidade da Sagrada Escritura e na Tradição viva da Igreja, essas palavras são a fonte principal para a catequese dos Mistérios do "princípio": criação, queda, promessa da salvação.

\section{Como citar este artigo:}

SILVA, Sueli Maria Ramos da. A reafirmação da fé no antigo relato da criação: uma abordagem semiótica do discurso católico. Estudos Semióticos, Número 2, São Paulo, 2006. Disponível em <www.fflch.usp.br/dl/semiotica/es>. Acesso em "dia/mês/ano".

${ }^{9}$ Cf. Gn 15, 5; Jr 33, 19-26.

${ }^{10} \mathrm{Cf}$. Is 44, 24.

${ }^{11}$ Cf. S1 104.

${ }^{12}$ Cf. Pr 8, 22-31. 